\title{
Intraspecific consistency and geographic variability in temporal trends of spring migration phenology among European bird species
}

\author{
Diego Rubolini ${ }^{1, *}$, Anders P. Møller ${ }^{2}$, Kalle Rainio ${ }^{3}$, Esa Lehikoinen ${ }^{3}$ \\ ${ }^{1}$ Dipartimento di Biologia, Università degli Studi di Milano, via Celoria 26, 20133 Milan, Italy \\ ${ }^{2}$ Laboratoire de Parasitologie Evolutive, Université Pierre et Marie Curie, Bât. A, 7ème étage, 7 quai St. Bernard, Case 237, \\ 75252 Paris Cedex 05, France \\ ${ }^{3}$ Department of Biology, University of Turku, 20014 Turku, Finland
}

\begin{abstract}
In the course of the 20th century, migratory birds have shown rapid phenological changes in response to climate change. However, the spatial variability of phenological changes, as well as their intraspecific consistency, remains largely unexplored. Here we analysed 672 estimates of change in first arrival dates of migratory birds and 289 estimates of mean/median arrival dates, based on time series with a minimum duration of 15 yr, collected across Europe from 1960 to 2006. There were highly significant advances in arrival date, significantly more so for first than mean arrival date. Change in arrival dates significantly varied among species, implying that response to climate change is a species-specific feature, and showed substantial phylogenetic effects, since ca. $50 \%$ of the variation in the observed trends was attributable to differences among species. The advance in first arrival date was weaker at extreme latitudes and stronger at intermediate latitudes, while geographic variation in mean arrival dates was less pronounced. Both first and mean arrival dates advanced the most for short- compared to long-distance migrants. These findings emphasize the reliability of estimates of phenological trends of avian species, which are therefore suitable to be included in comparative analyses aimed at identifying species-specific traits that favour adaptation to climatic changes. In addition, our results suggest that analyses of factors that have affected phenological responses to climate change should take into account spatial variation in the response, which could be due to spatial differences in the strength of climate change.
\end{abstract}

KEY WORDS: First arrival date $\cdot$ Long-distance migrants $\cdot$ Median arrival date $\cdot$ Repeatability · Short-distance migrants

Resale or republication not permitted without written consent of the publisher

\section{INTRODUCTION}

The changing global climate is having strong effects on the phenology of seasonal events (Walther et al. 2002, Parmesan \& Yohe 2003, Root et al. 2003, Lehikoinen et al. 2004, Ahas \& Aasa 2006, Menzel et al. 2006). The rising temperatures of the northern hemisphere led to an increase in the duration of the growing season in the course of the 20th century, thanks to milder winters and earlier onset of spring (Menzel \& Fabian 1999, Klein Tank et al. 2002, Stöckli \& Vidale 2004, Schwartz et al. 2006). An earlier onset of spring, with consequent advances in peak food sources, has been regarded as the main determinant of earlier timing of arrival and reproduction recorded among several populations of migratory birds (Both et al. 2004, Dunn 2004, Lehikoinen et al. 2004). Indeed, many studies have documented long-term shifts towards earlier migration, arrival, or breeding dates (reviewed in Dunn 2004, Lehikoinen et al. 2004, Gordo 2007, this issue), while changes in autumnal departure or migration timing have been less intensively investigated, and have been shown to depend on species-specific migration strategies (e.g. Jenni \& Kéry 2003). 
Changes in phenology could either be due to evolutionary changes, gene flow, or phenotypically plastic responses, although there are very few studies that have attempted to discriminate among these possibilities (Møller \& Merilä 2004, Gienapp et al. 2007, this issue, Pulido 2007, this issue). Unfortunately, simple phenological data do not allow a clear-cut discrimination among these hypotheses, which are, however, not mutually exclusive (see discussion in Jonzén et al. 2006, 2007a, Both 2007, Pulido 2007), since phenotypic plasticity may also have a genetic basis, so it can actually evolve (Nussey et al. 2005, Pigliucci 2005). Whatever the mechanism behind the observed changes, empirical data from prolonged time series extending well into the past suggest that migration and arrival dates show considerable variability, as reflected by several periods of constant directions of changes and subsequent shifts (Lehikoinen et al. 2004) that can often be related to short- or medium-term climatic oscillations (Ahola et al. 2004, Lehikoinen et al. 2004). Such adjustments do likely occur because of temporal variation in the intensity of selective pressures on optimal early arrival (Kokko 1999, Jonzén et al. 2007b, Møller 2007).

The most recent comprehensive review of the topic showed remarkable changes in migration/arrival dates in the course of the second half of the 20th century among Eurasian birds (Lehikoinen et al. 2004). It appears that, from the end of the 1960s, there has been a strong advance of arrival dates of several species of migratory birds, which seems to be unprecedented in historical time series dating back to 1750 (Lehikoinen et al. 2004). The overall rate of change in migration/ arrival dates during this period ranged between 2 and $4 \mathrm{~d}_{\text {decade }}{ }^{-1}$, depending on the phenological measure adopted (Lehikoinen et al. 2004). Therefore, recent climatic changes are likely to pose serious challenges to the plasticity of migratory behaviour (Coppack \& Both 2002). Moreover, not all populations or species may show the same degree of plasticity in response to warming patterns, and failure to track climatic changes may ultimately result in severe population declines (Both et al. 2006). Furthermore, Lehikoinen et al. (2004) suggested that long-distance migrants, spending the boreal winter in tropical areas, have advanced their migration to a lesser extent than shortdistance migrants, wintering in continental Europe or in the Mediterranean. This pattern could be expected because the consequences of global warming may be stronger in temperate rather than tropical areas, and because short-distance migrants are exposed to temperate climate all year round. A recent study, however, questioned its generality, by showing that in Fennoscandia long-distance passerine migrants have advanced arrival more consistently than short-distance ones in the period from 1980 to 2004, particularly in the early phase of migration (Jonzén et al. 2006; see also Gienapp et al. 2007). The overall picture of earlier spring arrival also shows geographic variability, which still has to be systematically explored (Lehikoinen et al. 2004).

The main aim of the present study was to assess the degree of intraspecific consistency of the response to recent climatic changes, by analysing trends in spring migration/arrival dates of European bird species, and to explore its phylogenetic and spatial variability. To this end, we collated information on changes in migration dates, expressed as days per year, from time series spanning between 1960 and 2006. Changes in migration dates were then analysed in relation to phylogenetic information and geographic location by means of mixed models. In addition, species were characterised as short- or long-distance migrants, in order to test whether there were consistent differences in the response to climate change according to migration strategy.

Assessing the degree of intraspecific consistency has important implications for predicting how different species will be able to cope with climatic changes. The existence of larger among- than within-species variation in long-term trends in spring phenology is in fact a basic prerequisite for considering the response to climate as a species-specific trait, which can be subsequently related to other traits in comparative analyses (see Spottiswoode et al. 2006). Such analyses may then unravel life-history traits that predict plasticity in migratory behaviour, which may thus provide a measure of the ability of a different species to face rapid climatic changes. To our knowledge, the assumption that intraspecific variation in the response to climate change is smaller than interspecific variation has never been empirically tested.

Moreover, spatial variability in the response to climate change may indicate that selective pressures towards earlier arrival vary among regions (e.g. Both et al. 2004, Both \& te Marvelde 2007, this issue). This may occur because warming patterns, which may ultimately affect migration/arrival dates, show geographical variation, and have been stronger in Central Europe compared to north-eastern Europe (Klein Tank et al. 2002, Schwartz et al. 2006, Both \& te Marvelde 2007).

In the present study, we did not separate arrival from migration data, though each reflects a different phenomenon (Gordo 2007), since there is no way (except in a few cases) to separate transient migrants from newly arriving individuals that would subsequently breed in the study area. Our dataset thus contained time series concerning both first arrival/migration dates (FADs) and mean/median arrival/migration dates 
(MEDs), which represent the 2 most commonly adopted measures of timing of migration or arrival dates in studies of birds (Lehikoinen et al. 2004, Sparks et al. 2005). FADs represent the day of the year of the first observation of a given species at a given site or region, while MEDs represent the mean/median day of passage or arrival of all the individuals of a given population. There are pros and cons for each of these 2 phenological traits, which are usually (though rather weakly) positively correlated (see Forchhammer et al. 2002, Møller \& Merilä 2004, Sparks et al. 2005). FADs are easily collected, and most of the time series analysed here refer to this measure. Moreover, FADs show a stronger dependence on climatic conditions than later phases of migration, and therefore temporal trends concerning FADs are generally stronger than trends concerning MEDs (Lehikoinen et al. 2004). On the other hand, FADs are sensitive to anomalous behaviour, may be based on male singing activity only (which is temperature sensitive; Gottlander 1987), and may be influenced by variation in, e.g., sampling effort or population size (see Sparks et al. 2001, 2005, Lehikoinen et al. 2004). MEDs are instead robust estimations of the response to climate change of a whole population of migrants. However, their main drawback is that they are usually collected at bird observatories only, where different geographical populations of migratory birds are intermixed (Lehikoinen et al. 2004, Knudsen et al. 2007, this issue). Moreover, temporal trends based on MED estimates usually refer to pooled samples of individuals of both sexes, which may differ in their response to climate change (e.g. Møller 2004; but see Rainio et al. 2007, this issue). The time series referring to MEDs are also quantitatively scarcer compared to those of FADs, due to the huge sampling efforts necessary for data collection, and may refer to a much reduced spectrum of species (usually passerines or near-passerines).

\section{METHODS}

\subsection{Data selection and species characteristics}

We retrieved as many observations as possible concerning time series of first spring arrival dates or mean/median arrival dates of European (west of the Ural Mountains and south to the Mediterranean) migratory bird species, both from published or unpublished sources (see Table 1, Fig. 1). This was done by making an extensive search of the ISI Web of Science combined with a search of all reference lists of all papers. For a given time series to be included in the analyses, we relied on the following criteria: (1) it had

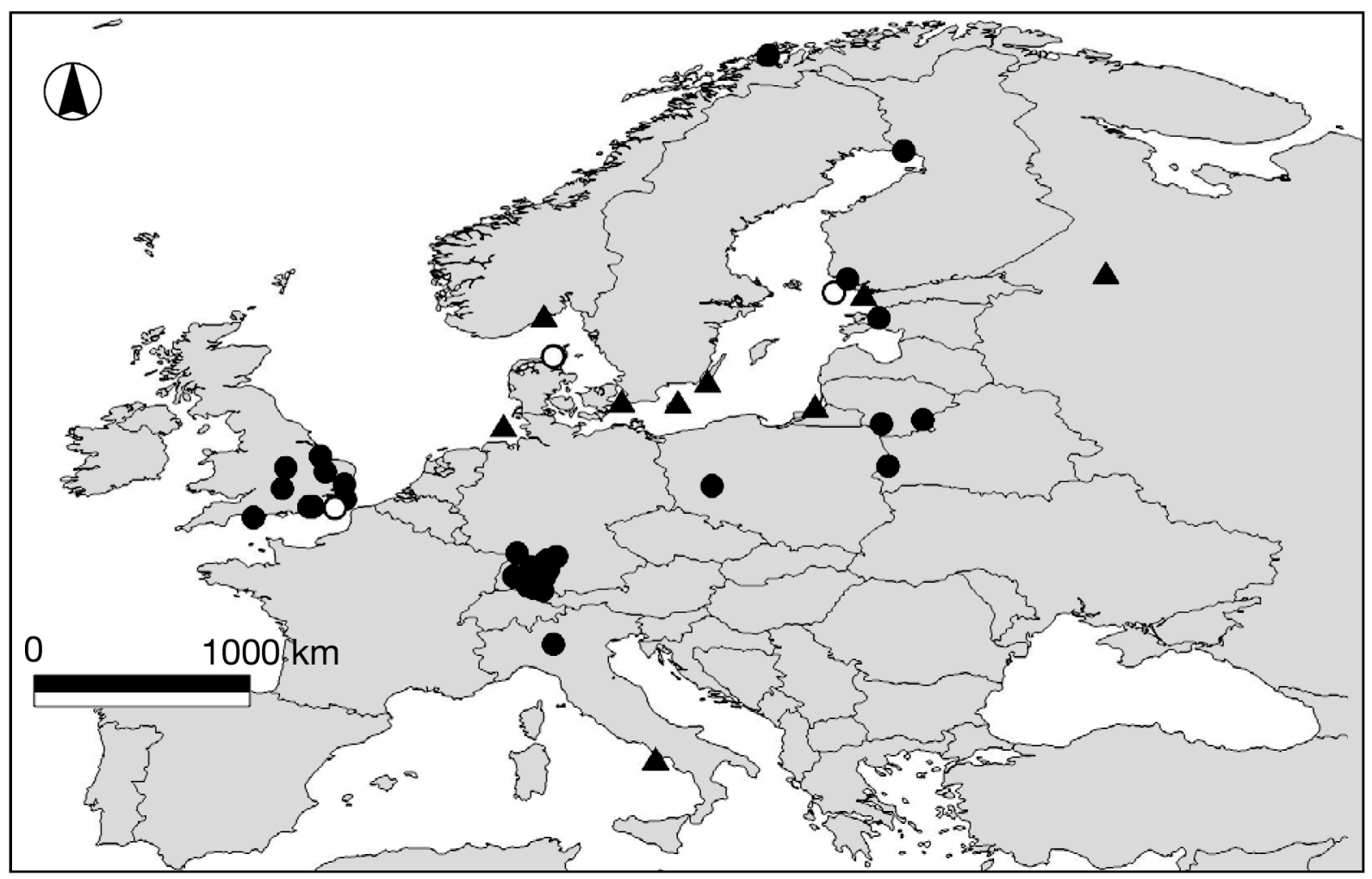

Fig. 1. Geographical location of sites for which time series of first arrival dates (๑), mean/median arrival dates ( $\mathbf{\Delta})$ or both (O) were retrieved. The exact coordinates, site names and number of time series are reported in Table 1 
Table 1. Number of time series for each site. Coordinates are decimal degrees north (latitude) or east (longitude; negative values corresponding to degrees west). Data type is coded as 0 (regional time series) or 1 (data collected by means of standardized routines) (see Section 2). Sites are sorted from south to north. FAD: first arrival date; MED: mean/median arrival date; superscripted references give details of data collection methods. ${ }^{a}$ Jonzén et al. (2006), Saino et al. (2007, this issue); ${ }^{b}$ Zalakevicius \& Zalakeviciute (2001); ${ }^{\mathrm{C}}$ Møller et al. (2004); ${ }^{\mathrm{d}}$ Rainio et al. (2006); ${ }^{\mathrm{e}}$ Lehikoinen et al. (2004); ${ }^{\mathrm{f}}$ Rauhala (1994); ${ }^{\mathrm{g}}$ recalculated from published data

\begin{tabular}{|c|c|c|c|c|c|c|}
\hline \multirow[t]{2}{*}{ Site } & \multirow[t]{2}{*}{ Lat. } & \multirow[t]{2}{*}{ Long. } & \multirow[t]{2}{*}{ Data type } & \multicolumn{2}{|c|}{ Time series } & \multirow[t]{2}{*}{ Source } \\
\hline & & & & FAD & MED & \\
\hline Capri & 40.55 & 14.25 & 1 & - & 9 & F. Spina et al. (unpubl. data) ${ }^{a}$ \\
\hline Borgo S. Giacomo & 45.33 & 10.00 & 1 & 4 & _- & Rubolini et al. (2007) \\
\hline Lindau & 47.55 & 9.53 & 1 & 11 & - & Peintinger \& Shuster (2005) \\
\hline Konstanz & 47.65 & 9.17 & 1 & 2 & - & Peintinger \& Shuster (2005) \\
\hline Radolfzell & 47.73 & 8.92 & 1 & 9 & - & Peintinger \& Shuster (2005) \\
\hline Bad Buchau & 48.08 & 9.62 & 1 & 10 & - & Peintinger \& Shuster (2005) \\
\hline Sigmaringen & 48.08 & 9.22 & 1 & 3 & - & Peintinger \& Shuster (2005) \\
\hline St.Georgen/Schwarzwald & 48.12 & 8.33 & 1 & 12 & - & Peintinger \& Shuster (2005) \\
\hline Gingen/Fils & 48.39 & 9.77 & 1 & 12 & _- & Peintinger \& Shuster (2005) \\
\hline Eningen/Reutlingen & 48.48 & 9.25 & 1 & 5 & - & Peintinger \& Shuster (2005) \\
\hline Tübingen & 48.52 & 9.05 & 1 & 9 & - & Peintinger \& Shuster (2005) \\
\hline Göppingen & 48.70 & 9.65 & 1 & 3 & - & Peintinger \& Shuster (2005) \\
\hline Remstal & 48.78 & 9.73 & 1 & 15 & - & Peintinger \& Shuster (2005) \\
\hline Ellwangen & 48.96 & 10.13 & 1 & 1 & - & Peintinger \& Shuster (2005) \\
\hline Stutensee/Karlsruhe & 49.08 & 8.48 & 1 & 11 & - & Peintinger \& Shuster (2005) \\
\hline Portland & 50.57 & -2.47 & 1 & 1 & - & Browne \& Aebischer (2003) \\
\hline Dungeness & 50.93 & 0.93 & 1 & 3 & 2 & $\begin{array}{l}\text { Sparks et al. (2005), } \\
\text { Browne \& Aebischer (2003) }\end{array}$ \\
\hline Essex & 51.00 & 0.00 & 0 & 5 & - & Sparks \& Mason (2001) \\
\hline Sussex & 51.00 & -0.17 & 0 & 14 & - & Loxton et al. (1998) \\
\hline Sandwich Bay & 51.32 & 1.35 & 1 & 1 & - & Browne \& Aebischer (2003) \\
\hline Oxfordshire region & 51.75 & -1.25 & 0 & 20 & - & Cotton (2003) \\
\hline Wielkopolska region & 51.85 & 16.58 & 1 & 16 & - & Tryjanowski et al. (2002) \\
\hline Landguard & 51.93 & 1.32 & 1 & 1 & - & Browne \& Aebischer (2003) \\
\hline Holme & 52.45 & 0.52 & 1 & 1 & - & Browne \& Aebischer (2003) \\
\hline Leicestershire & 52.63 & -1.13 & 0 & 8 & - & Loxton et al. (1998) \\
\hline Bialowieza & 52.70 & 23.87 & 1 & 1 & - & Mitrus et al. (2005) \\
\hline Gibraltar Point & 53.10 & 0.32 & 1 & 1 & - & Browne \& Aebischer (2003) \\
\hline Helgoland & 54.33 & 7.92 & 1 & - & 24 & Нüррор \& Нüррор (2003) \\
\hline Zuvintas & 54.43 & 23.58 & 1 & 56 & - & M. Zalakevicius (unpubl. data) ${ }^{\mathrm{b}}$ \\
\hline Vilnius & 54.60 & 25.30 & 1 & 39 & - & Zalakevicius et al. (2006) \\
\hline Rybachiy & 55.17 & 20.85 & 1 & - & 27 & Sokolov et al. $(1998)^{g}$ \\
\hline Christiansø & 55.32 & 15.18 & 1 & - & 25 & Tøttrup et al. (2006) \\
\hline Falsterbo & 55.38 & 12.83 & 1 & - & 23 & E. Knudsen et al. (unpubl. data) ${ }^{a}$ \\
\hline Ottenby & 56.20 & 16.40 & 1 & - & 35 & $\begin{array}{l}\text { Stervander et al. (2005), } \\
\text { E. Knudsen et al. (unpubl. data) }\end{array}$ \\
\hline Kraghede & 57.20 & 10.00 & 1 & 1 & 1 & A. P. Møller (unpubl. data) ${ }^{\mathrm{c}}$ \\
\hline Northern Denmark & 57.20 & 9.97 & 1 & 1 & 1 & A. P. Møller (unpubl. data) \\
\hline Matsalu & 58.83 & 23.48 & 1 & 8 & - & Sokolov et al. $(1998)^{g}$ \\
\hline Jomfruland & 58.88 & 9.62 & 1 & - & 19 & E. Knudsen et al. (unpubl. data) ${ }^{a}$ \\
\hline Hanko & 59.80 & 22.88 & 1 & - & 16 & E. Knudsen et al. (unpubl. data) ${ }^{\mathrm{a}}$ \\
\hline Jurmo & 59.83 & 21.62 & 1 & 106 & 106 & E. Lehikoinen et al. (unpubl. data) ${ }^{\mathrm{d}, \mathrm{e}}$ \\
\hline Turku & 60.43 & 22.20 & 1 & 162 & - & E. Lehikoinen et al. (unpubl. data) ${ }^{\mathrm{e}}$ \\
\hline Ladoga & 60.68 & 32.93 & 1 & - & 1 & Sparks et al. (2005) \\
\hline Kemi & 65.75 & 24.53 & 1 & 118 & - & P. Suopajärvi et al. (unpubl. data) ${ }^{\mathrm{f}}$ \\
\hline Tromsø & 69.70 & 18.90 & 0 & 2 & - & Barrett (2002) \\
\hline
\end{tabular}

to start no earlier than 1960, (2) span over at least $15 \mathrm{yr}$, and (3) report the slope of the phenological variable over time, expressed in days per year, from a simple linear regression analysis. Slopes from analyses of non-linear trends or from multiple regression analyses are thus not considered in this paper. In a few instances, trends were recalculated based on published data (see Table 1). Time series starting earlier than 1960 were discarded to limit the potentially confounding effects of non-linear temporal trends in arrival dates, and because most global warming is believed to have occurred after 1970 (IPCC 2001). When $>1$ time series for a given species was available for a given site, we considered only the one spanning the greatest number of years. In assembling the dataset, we have tried to minimise the effect of publication bias by including all the available time series for a given location (irrespective of the sign of the trend), and by including data from several unpublished sources (Table 1). 
Overall, 672 FAD time series, derived from 184 species, and 289 MED time series, from 113 species, satisfied these criteria. Most time series were from Finland (FAD: $57 \%$; MED: $42 \%$ ) (Table 1). The mean start year of the FAD time series was 1968 (range: 1963 to 1983) and the mean final year was 2000 (1992 to 2006). These statistics for MED time series were similar (mean start year: 1973, range: 1960 to 1983; mean final year: 2000, range: 1990 to 2005). The mean $( \pm \mathrm{SE})$ duration of FAD time series was $30.6 \pm 0.2$ yr (range: 16 to $38 \mathrm{yr}$ ), while the mean $( \pm \mathrm{SE})$ duration of MED time series was $26.5 \pm$ 0.4 yr (range: 16 to $42 \mathrm{yr}$ ).

For each time series, we coded latitude and longitude of the site of data collection (Table 1, Fig. 1). Where the data were collected over a wide geographical region (e.g. Loxton et al. 1998, Cotton 2003), we reported the midpoint coordinates of that region. Hereafter, the term 'site' may either refer to a specific and clearly identifiable geographic location, or to a wider geographical area, depending on the scale of data collection in the original source. In an attempt to control for sampling effort, we recorded whether data were collected using standardized sampling routines (e.g. data from bird observatories, ringing data), or by casual observations within wider areas (regional time series).

For each species, we coded the phylogenetic information at the above-species level according to the tapestry phylogeny of Sibley \& Ahlquist (1990). We considered the following above-species taxonomic groupings: genus, subfamily, family and order. When no subfamily was available, we used the family code as well for this category. These levels were then used to quantify phylogenetic effects on changes in arrival date (see Section 2.2). Finally, for each species, we recorded the migratory habit, i.e. whether a species was a short- or long-distance migrant. Because this coding was not straightforward for some species, due to inter-population differences in migratory behaviour (e.g. the blackcap Sylvia atricapilla; Berthold et al. 1992), we adopted the following simple rule of thumb: we defined a given species as a long-distance migrant if most populations migrate to Africa or the Middle East during winter, while all other species, mainly wintering within Europe or within the Mediterranean basin, were categorized as short-distance migrants. Migratory habits were classified based on information in Cramp (1998).

\subsection{Statistical analyses}

Phylogenetic variance components were analysed by mixed models (REML method), where slopes were considered as the dependent variable and taxonomic codes (species, genus, subfamily, family, order) as nested random-effect factors. Site was included as a fixed factor to account for any geographic variability. We carried out different models for FADs and MEDs. Concerning FAD trends, we also initially tested whether there was any difference in phenological trends associated with data type (standardized vs. regional data, see Section 2.1). However, since this factor did not affect the magnitude of FAD trends (details not shown), we discarded it from further analyses (based on raw data, the mean slopes [and 95\% confidence limits, CL] for standard effort time series vs. regional time series were as follows: $-0.371 \mathrm{~d} \mathrm{yr}^{-1}$ [95\% CL: -0.399 to $-0.342, \mathrm{n}=623$ ] vs. $-0.368 \mathrm{~d} \mathrm{yr}^{-1}$ [95\% CL: -0.445 to $-0.292, \mathrm{n}=49]$ ).

To explore whether the among-species variation in trends was significantly larger that the within-species variation, and to assess geographic variability in phenological trends, we analysed trends in FADs or MEDs by means of mixed models, where latitude, longitude and their squared terms were the independent variables, while species was included as a fixed factor, and site as a random factor. The initial year of each time series and its squared term were also included in the model as covariates to test for temporal changes in strength or direction of trends in migration/arrival dates. We obtained parsimonious models (minimal adequate models; Crawley 1993) by sequentially removing non-significant $(\mathrm{p}>0.05)$ fixed effect terms, until they contained only significant predictors. To analyse differences in trends in FADs or MEDs according to migratory habit (long- vs. short-distance migrant), we compared the least-square means of the effect of species (derived from the above-mentioned models) by means of $t$-tests.

As the accuracy of the dependent variable (slope in days per year) could depend on the number of years over which the trend was calculated, in all models we also included the number of years for a given slope as a weighting factor. However, weighted analyses did not qualitatively differ from unweighted ones in any of the models (details not reported for brevity), so we report only results from unweighted analyses.

Mixed model analyses were performed by means of SAS software (v. 9.0).

\section{RESULTS}

\subsection{Descriptive statistics and general patterns}

The mean slope for FAD time series was $-0.370 \mathrm{~d} \mathrm{yr}^{-1}$ (95\% CL: -0.397 to $-0.343, \mathrm{n}=672$ ), while that for MED time series was $-0.158 \mathrm{~d} \mathrm{yr}^{-1}$ (95\% CL: -0.186 to -0.132 , $\mathrm{n}=289$ ) (Fig. 2). Therefore, in the past 47 yr FADs have advanced more than MEDs. Indeed, when species-spe- 
cific mean FAD slopes were compared with mean MED slopes of the same species in a pairwise test, a highly significant difference emerged (paired-samples $t$-test, mean \pm SE difference $=-0.28 \pm 0.03 \mathrm{~d} \mathrm{yr}^{-1}, t=-9.50, \mathrm{p}<$ $0.0001, \mathrm{n}=112$ species for which both measures were available). This was true both for short- (paired-samples $t$-test, mean $\pm \mathrm{SE}$ difference $=-0.34 \pm 0.04 \mathrm{~d} \mathrm{yr}^{-1}$, $t=-8.07, \mathrm{p}<0.0001, \mathrm{n}=72)$ and long-distance migrants (paired-samples $t$-test, mean \pm SE difference $=-0.19 \pm$ $0.03 \mathrm{~d} \mathrm{yr}^{-1}, t=-5.89, \mathrm{p}<0.0001, \mathrm{n}=40$ ).

Trends in FADs were positively correlated with trends in MEDs (based on mean species-specific slopes, $\mathrm{r}=0.33, \mathrm{p}<0.001, \mathrm{n}=112$ species). This result was the spurious outcome of a difference in trends between short- and long-distance migrants (see below), because the correlation disappeared when performed for each group of species separately (short-distance migrants, $\mathrm{r}=0.14, \mathrm{p}=0.25, \mathrm{n}=72$; long-distance migrants, $\mathrm{r}=0.18, \mathrm{p}=0.28, \mathrm{n}=40$ ). We repeated this analysis by only including species for which we had a FAD and a MED trend for the same site, to avoid con-

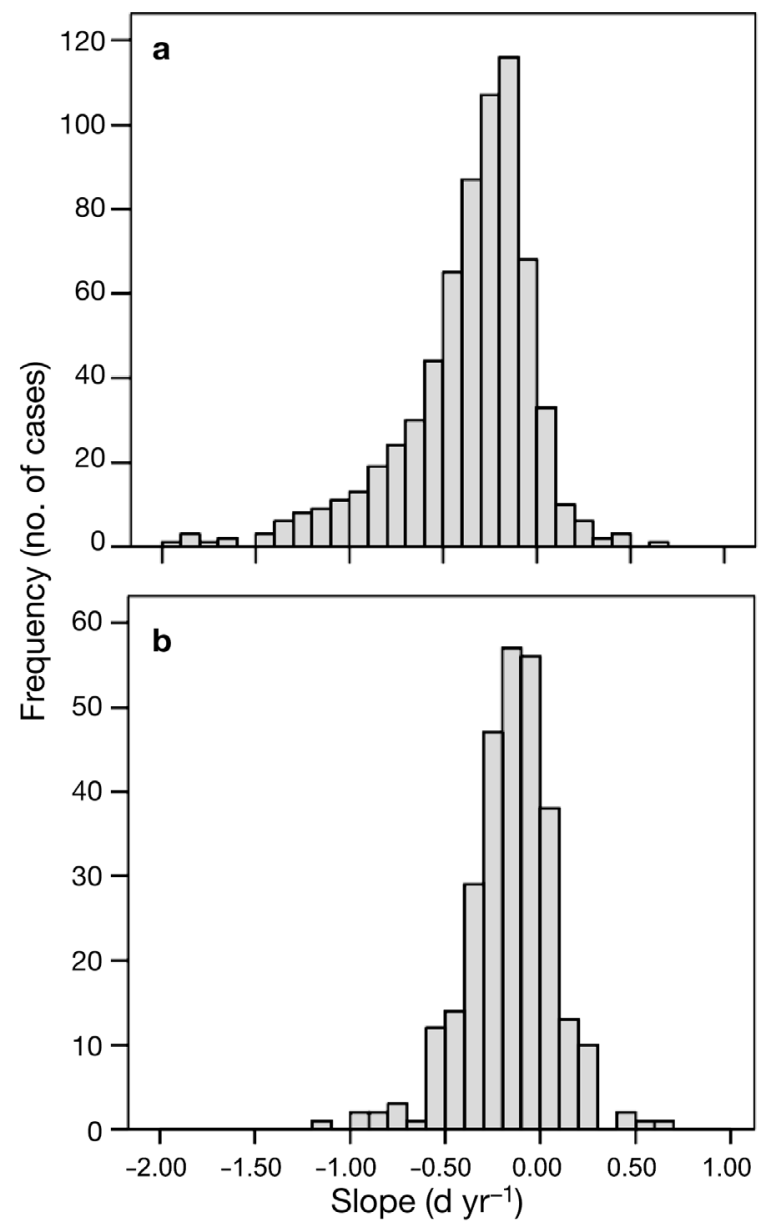

Fig. 2. Frequency distribution of trends in spring (a) first arrival and (b) mean/median migration dates among European bird species during the period from 1960 to 2006 founding effects of pooling time series of a given species originating from different sites $(n=110$ species in total, of which 106 were from Jurmo bird observatory, Finland; see Table 1). In this restricted dataset, the overall correlation between trends in FADs and MEDs was again positive and highly significant $(\mathrm{r}=0.36, \mathrm{p}<$ $0.0001)$. This pattern was due to long-distance migrants only $(\mathrm{r}=0.43, \mathrm{p}=0.005, \mathrm{n}=40)$, while no significant correlation was observed among short-distance migrants $(\mathrm{r}=0.07, \mathrm{p}=0.55, \mathrm{n}=70)$. The difference between the 2 correlation coefficients was marginally non-significant $(z=1.90, p=0.057)$. Thus, it appears that, when geographic variation in species-specific long-term trends is accounted for by considering only FAD and MED trends for the same site, there is a correlation between changes in FAD and MED, at least among long-distance migrants. The lack of a correlation among short-distance migrants may be due to the much larger among-year variability of FADs of such species compared to those of MEDs. In fact, early arriving, short-distance migrants may make use of even short early warm spells that vary greatly in time and space, while later arriving, long-distance migrants are unable to respond to such early weather variability (see Section 4).

\subsection{Phylogenetic effects}

To estimate phylogenetic effects on changes in FADs and MEDs, we performed a mixed model analysis. Site was included as a fixed factor to account for geographical variation in long-term trends.

The mixed model analysis revealed that phylogenetic effects in FAD trends accounted for substantial amounts of variance at the levels of species within genera, genus within subfamilies, subfamily within orders, and order (Table 2), while variance at the level of family (within orders) could not be estimated due to the low number of levels. The total variance among species was equal to $48.4 \%$ of the variance in the observed FAD slopes, and the estimated SD of the effects of species, when tested alone in the model, was 0.23 (95\% CL: 0.20 to 0.28 ) $\mathrm{d} \mathrm{yr}^{-1}$. MED trends showed phylogenetic effects at the levels of order and species (within orders), though the latter variance component had a high degree of uncertainty (Table 2). Variance components due to genus (within subfamily), subfamily (within family) and family (within order) could not be estimated due to the low number of levels. Overall, the total variance among species was equal to $50.5 \%$ of the variance in MED trends (Table 2).

In both models, among-site variation was an important source of variation in changes in migration dates, thus indicating marked geographic variability (Table 2; see also Section 3.3). 
Table 2. Mixed model analyses of variance of trends in first arrival dates (FAD) and mean/median arrival dates (MED) in relation to phylogeny and site. \% variance calculated within phylogenetic effects (i.e. excluding residual variance). CL: confidence limits. Degrees of freedom (df) of the fixed effects are estimated by the Satterthwaite's approximation

\begin{tabular}{|c|c|c|c|}
\hline $\begin{array}{l}\text { FAD } \\
\text { Random part }\end{array}$ & $\mathrm{SD}$ & $95 \% \mathrm{CL}$ & $\%$ variance \\
\hline Order & 0.161 & $0.090-0.638$ & 39.2 \\
\hline Family ${ }^{a}$ & - & - & - \\
\hline Subfamily ${ }^{b}$ & 0.138 & $0.090-0.292$ & 28.9 \\
\hline Genus $^{\mathrm{c}}$ & 0.107 & $0.072-0.208$ & 17.3 \\
\hline Species $^{\mathrm{d}}$ & 0.098 & $0.067-0.179$ & 14.5 \\
\hline Residual & 0.265 & $0.249-0.283$ & \\
\hline Fixed effect & $F$ & df & $\mathrm{p}$ \\
\hline Site & 5.33 & 34,498 & $<0.0001$ \\
\hline \multicolumn{4}{|l|}{ MED } \\
\hline Random part & $\mathrm{SD}$ & $95 \% \mathrm{CL}$ & $\%$ variance \\
\hline Order & 0.205 & $0.105-1.486$ & 95.5 \\
\hline Family $^{\mathrm{a}}$ & - & - & - \\
\hline Subfamily ${ }^{\mathrm{a}}$ & - & - & - \\
\hline Genus $^{\mathrm{a}}$ & - & _- & - \\
\hline Species $^{\mathrm{e}}$ & 0.044 & $0.018-7.237$ & 4.5 \\
\hline Residual & 0.208 & $0.188-0.233$ & \\
\hline Fixed effect & $F$ & $\mathrm{df}$ & $\mathrm{p}$ \\
\hline Site & 4.87 & 12,267 & $<0.0001$ \\
\hline \multicolumn{4}{|c|}{$\begin{array}{l}{ }^{\mathrm{a}} \text { Non-estimable variance components; }{ }^{\mathrm{b}} \text { subfamily(order); } \\
{ }^{c} \text { genus(subfamily order); }{ }^{\mathrm{d}} \text { species(genus subfamily order); } \\
{ }^{\mathrm{e}} \text { species(order) }\end{array}$} \\
\hline
\end{tabular}

the slopes, with a relatively low level of uncertainty $\left(\mathrm{SD}=0.105 \mathrm{~d} \mathrm{yr}^{-1}, 95 \%\right.$ CL: 0.074 to 0.182 ; Table 3). These results were unaffected by including either latitude or longitude (which were positively correlated in the present sample of FAD sites, $r=0.73$ ) separately in the model (details not shown).

Short-distance migrants advanced FADs more than long-distance migrants (model-derived least-squares means $\pm \mathrm{SE}_{,}-0.56 \pm 0.03 \mathrm{~d} \mathrm{yr}^{-1}, \mathrm{n}=104$ species vs. $-0.22 \pm 0.02 \mathrm{~d} \mathrm{yr}^{-1}, \mathrm{n}=80$ species, respectively; $t$-test for unequal variances, $t_{174.8}=8.67, \mathrm{p}<0.001$ ). The variance in FAD trends was greater among short-compared to long-distance migrants (variance estimates: 0.11 vs. $0.05, F_{79,103}=0.39, \mathrm{p}<0.001$ ).

The model concerning MED trends confirmed the existence of significant differences among species, and indicated that trends showed some geographic variability, which however differed from that observed among FAD time series (Table 3). In fact, there was non-linear longitudinal variation, with a stronger advance towards eastern and western longitudes, and less pronounced advances in Central Europe (Fig. 3, Table 3). Moreover, there was a significant tendency towards increasing earliness in MED trends in more recent years (Table 3), while the effect of the squared term of initial year was not significant (details not shown). The non-linear longitudinal trend was, however, entirely due to the 3 extreme data points ( 2 in the east and 1 in the west; see Fig. 3), because their removal considerably increased the uncertainty of

\subsection{Intraspecific consistency, geographic variation and migratory habits}

In the following analyses, we explored inter-specific and geographic variation in long-term trends, and the effect of migratory habit (see Section 2). In initial models that were subjected to a step-down simplification procedure, we thus included species, latitude, longitude and their squared terms as fixed effects, and site as a random effect.

The model concerning FAD trends showed significant differences among species, as well as non-linear latitudinal patterns, the advancement being weaker towards both southern and northern latitudes, with stronger effects at intermediate latitudes (Table 3, Fig. 3). No significant longitudinal variation in FAD trends was detected, and there was no significant effect of the initial year of each time series (details not shown). Among-site variation amounted to $14.2 \%$ of the total variance in
Table 3. Test statistics and estimates of effects on trends in first arrival dates (FAD) and mean/median arrival dates (MED) in relation to species, latitude and longitude, and initial year of time series, while taking among-site variation into account. CL: confidence limits. Degrees of freedom (df) of the fixed effects are estimated by the Satterthwaite's approximation

\begin{tabular}{|c|c|c|c|c|}
\hline $\begin{array}{l}\text { FAD } \\
\text { Random part }\end{array}$ & $\mathrm{SD}$ & $95 \% \mathrm{CL}$ & \% variance & \\
\hline Site & 0.105 & $0.074-0.182$ & 14.2 & \\
\hline Residual & 0.257 & $0.242-0.275$ & & \\
\hline Fixed effects & $F$ & $\mathrm{df}$ & $\mathrm{p}$ & Estimate (SE) \\
\hline Species & 3.42 & 183,469 & $<0.001$ & - \\
\hline Latitude & 6.49 & $1,35.6$ & 0.015 & $-0.226(0.089)$ \\
\hline Latitude $^{2}$ & 7.06 & $1,35.3$ & 0.012 & $0.002(0.001)$ \\
\hline \multicolumn{5}{|l|}{ MED } \\
\hline Random part & SD & $95 \%$ CL & \% variance & \\
\hline Site & 0.117 & $0.073-0.287$ & 38.1 & \\
\hline Residual & 0.191 & $0.172-0.214$ & & \\
\hline Fixed effects & $F$ & df & $\mathrm{p}$ & Estimate (SE) \\
\hline Species & 1.72 & 112,164 & $<0.001$ & - \\
\hline Longitude & 8.12 & 1, 23.8 & 0.009 & $0.060(0.020)$ \\
\hline Longitude $^{2}$ & 6.02 & 1,30 & 0.020 & $-0.002(0.0006)$ \\
\hline Initial year & 8.15 & $1,44.2$ & 0.007 & $-0.011(0.004)$ \\
\hline
\end{tabular}




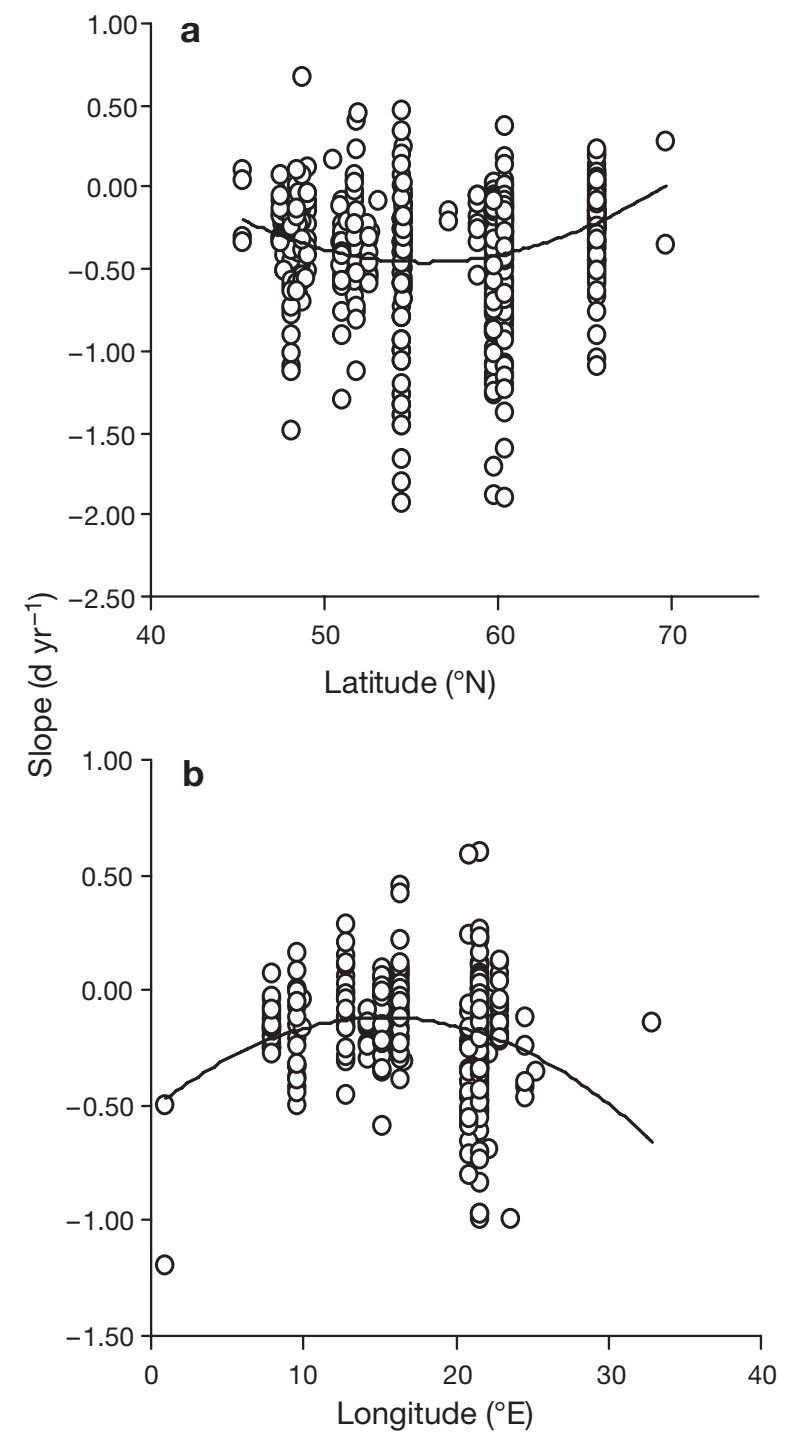

Fig. 3. Trends in (a) first arrival date (FAD) in relation to latitude and (b) mean/median migration date (MED) in relation to longitude. The lines represent second-order polynomial regressions with the following equations (SE in parentheses): (a) FAD slope $=6.978(1.324)-0.267(0.047) \times$ latitude + $0.002(0.001) \times$ latitude $^{2}\left(F_{2,669}=19.5, \mathrm{p}<0.0001\right)$ and $(\mathrm{b})$ MED slope $=-0.497(0.111)+0.048(0.015) \times$ longitude $-0.002(0.001)$ $\times$ longitude $^{2}\left(F_{2,286}=5.25, \mathrm{p}=0.006\right)$. The estimates of the non-linear longitudinal trend reported in (b) were heavily dependent on the 3 extreme data points (2 east and 1 west, see Section 3.3)

longitude estimates (statistics at removal from the model: longitude ${ }^{2}$, estimate $\pm \mathrm{SE}=-0.002 \pm 0.002 \mathrm{~d}$ $\mathrm{yr}^{-1}, F_{1,6.23}=0.98, \mathrm{p}=0.36$; longitude, estimate $=0.002$ $\left.\pm 0.008 \mathrm{~d} \mathrm{yr}^{-1}, F_{1,6.33}=0.04, \mathrm{p}=0.84\right)$. The results concerning the other variables in the model were qualitatively unaffected by removal of the extreme data (details not shown). The among-site variation accounted for $38.1 \%$ of the total variance in MED trends, though with a substantial degree of uncertainty
$\left(\mathrm{SD}=0.117 \mathrm{~d} \mathrm{yr}^{-1}, 95 \%\right.$ CL: 0.073 to 0.287 ; Table 3). These results were unaffected by including either latitude or longitude (which were positively correlated in the present sample of MED sites, $r=0.49$ ) separately in the model (details not shown).

Similarly to FADs, short-distance migrants advanced MEDs more than long-distance migrants (modelderived least-squares means $\pm \mathrm{SE},-0.21 \pm 0.03 \mathrm{~d} \mathrm{yr}^{-1}$, $\mathrm{n}=73$ species vs. $-0.01 \pm 0.03 \mathrm{~d} \mathrm{yr}^{-1}, \mathrm{n}=40$ species, respectively; $\left.t_{111}=4.97, \mathrm{p}<0.001\right)$. The variance in MED trends did not significantly vary according to migratory habit $\left(F_{39,72}=0.58, \mathrm{p}=0.07\right)$, though there was a tendency towards larger variance in short-compared to long-distance migrants (variance estimates: 0.05 vs. 0.03).

Finally, a significant degree of intraspecific consistency in phenological trends was further confirmed by simple mixed models with site as a random effect and species as a fixed factor (effect of species, FADs: $F_{183,469}=3.39, \mathrm{p}<0.001 ;$ MEDs: $F_{112,155}=1.57, \mathrm{p}=$ 0.005).

\section{DISCUSSION}

We analysed the most extensive dataset so far of changes in spring arrival dates of migratory birds in order to quantify sources of variation in phenological data due to climate change. There were rapid advances in arrival date, especially for FADs, that are likely to be most influenced by climatic amelioration (e.g. Lehikoinen et al. 2004, Vähätalo et al. 2004). The overall advances we documented $\left(0.37\right.$ and $0.16 \mathrm{~d} \mathrm{yr}^{-1}$ for FADs and MEDs, respectively) were similar to those reported in Lehikoinen et al. (2004), which is not surprising given the extensive overlap between the sets of data used in the 2 studies. There were clear differences in response among species, after accounting for differences among study sites, implying that the response to climate change was species specific. Furthermore, we found evidence of significant effects of geographic location and migratory habits, with short-distance migrants advancing arrival/migration dates more than long-distance migrants, and trends in MED dates showed a tendency towards increasing earliness in more recent years. We will briefly discuss these results.

The main novel finding of the present study was that change in spring arrival date (either first or mean date) was significantly repeatable among species. This implies that if we sample 2 populations of the same species, we are likely to have a more similar phenological response to climate change than if we sampled 2 random populations from different species. Thus, there is reason to believe that species-specific characteristics related to general ecology (such as variation in 
distribution range or timing of spring migration) or life history account for such interspecific differences in response to climate change. Such repeatability is an important prerequisite for reliable comparative analyses, because an absence of repeatability would imply that there are little or no interspecific differences among species to explain (Møller \& Birkhead 1994).

Phylogenetic effects on the response to climate change were investigated by means of mixed models. We documented substantial phylogenetic effects on trends in both FADs and MEDs, since ca. $50 \%$ of the variance in observed trends could be attributed to differences among species. Furthermore, estimates of variance components at the above-species levels suggest that future studies analysing multi-species responses to climate change should consider the opportunity of taking into account shared phylogenetic history, because species that are more closely related would tend to show more similar responses compared to distantly related ones (Felsenstein 1985, Harvey \& Pagel 1991).

We found evidence of geographical and temporal variation in the changes in timing of migration/arrival, as shown by effects of latitude and longitude on the magnitude of the effect, and by the tendency towards a stronger advancement of MED in recent years. Climate change is far from evenly distributed around the year, and different geographic locations have experienced considerable heterogeneity in climatic amelioration (Klein Tank et al. 2002, Moberg et al. 2006, Schwartz et al. 2006, Both \& te Marvelde 2007). For example, it is mainly spring temperatures and thus the start of the growing season that have advanced in Europe, an effect which is most pronounced at intermediate latitudes (Klein Tank et al. 2002, Schwartz et al. 2006). Although we did not match climate change at specific geographic locations with changes in phenology (Both et al. 2004, Both \& te Marvelde 2007), our results suggest that the spatial distribution of change in FADs may parallel the spatial distribution of changes in weather conditions during spring. On the other hand, results concerning geographical variation of MED trends are more difficult to interpret due to the existence of wider gaps in geographical coverage compared to FAD trends, and because of the heavy dependence of the longitudinal variation on a few extreme data points (see Fig. 3). In this context, further analyses at the intraspecific level may tackle the issue of the spatial correlation of the changes in timing of migration/arrival. Indeed, it could be predicted that, if local weather conditions are the main determinants of phenological changes of a given species, the correlation between phenological trends recorded at different sites should decrease with increasing distance among sites. Finally, the observed tendency towards in- creasing earliness in MED (but not in FAD) trends in recent years, independently of geographic variability in trends, is consistent with the reported stronger temperature increase in Europe from 1976 onwards (IPCC 2001), thus corroborating the link between temperature increase and advances in arrival dates of birds.

A number of different studies have investigated whether migration distance affects response to climate change. Originally, it was proposed that long-distance migrants that often winter 1000s of kilometres away from their breeding locations would be unable to adjust their migration phenology to climate change (Berthold 1991). This may not hold if different major weather patterns show significant covariation between wintering and breeding areas, as had been advocated earlier (e.g. Forchhammer et al. 2002; see also Saino \& Ambrosini 2007). The recent review by Lehikoinen et al. (2004) suggested that long-distance migrants had shown a weaker response to climate change than short-distance migrants. This was questioned by a recent study based on standardized time series from 4 Fennoscandian bird observatories over the period from 1980 to 2004, the results showing that long-distance passerine migrants had in fact advanced their arrival date the most, regardless of the trend in a major climate pattern, the North Atlantic Oscillation (NAO) (Jonzén et al. 2006), which is well known to affect the timing of spring arrival in birds (Hüppop \& Hüppop 2003, Vähätalo et al. 2004, Stervander et al. 2005). It is thus possible that the discrepancy between our findings, showing clear evidence of a stronger advance among short- compared to long-distance migrants, and those reported in Jonzén et al. (2006) could be due to the many differences between the 2 studies, such as a different temporal extent of the time series, showing different temporal trends in environmental variables (like the NAO), a different geographical coverage, as well as differences in the taxonomic composition of the samples, since the Jonzén et al. (2006) study considered only small passerine species, whereas our study included data from both passerines and non-passerines showing a huge variation in body size, habitat (landbirds and waterbirds) and ecological attributes. In any case, it seems obvious that any generalization of the results reported in Jonzén et al. (2006) appears premature.

We speculate that differences in timing of arrival between short- and long-distance migrants could contribute to the observed pattern. All else being equal, long-distance migrants reach the breeding grounds considerably later than short-distance migrants (Cramp 1998, Lehikoinen et al. 2004), and thus encounter more benign conditions along the migration route due to the advancement of spring and consequent improvement of meteorological conditions. It is therefore likely that 
long-distance migrants have shown a weaker response to earlier onset of spring compared to short-distance migrants, as the latter may adopt a 'hopeful strategy', whereby some individuals, especially in the earlier phases of migration, try to reach the breeding grounds as soon as they perceive signs that late winter-early spring weather is improving. This may also partly apply to some earlier arriving, long-distance migrants, and may explain the stronger response in FADs compared to MEDs observed among both short- and long-distance migrants (Lehikoinen et al. 2004, present study).

Although our analyses were based on the most extensive datasets available, some methodological issues have to be addressed. For example, first arrival dates are subject to the influence of sampling effort to a much higher degree than mean arrival dates (Sparks et al. 2001, 2005, Lehikoinen et al. 2004). Such problems of sampling effort may seem less important than previously thought, because we did not find any effect of the degree of standardization in data collection on estimates of change, i.e. the rate of change in migration dates was similar between data collected by means of standardized routines and non-standardized data collected over wider regions. Moreover, first arrival dates showed a high degree of intraspecific consistency, which may indicate that this measure appropriately describes species-specific responses to climate changes. A second problem that is rarely considered is that the actual shape of the frequency distributions may change in response to climate change (Lehikoinen et al. 2004, Sparks et al. 2005). Such changes could be important for analyses of phenological data if first or mean arrival dates are extracted, or if specific frequency distributions are fitted to the data under the assumption of a normally distributed variable (see discussion in Knudsen et al. 2007). Analysing shapes of frequency distributions of phenological data cannot readily be done, because data derived from bird observatories may be biased for other reasons, such as the number and relative size of the different breeding populations contributing to overall frequency distributions (see discussion in Knudsen et al. 2007). Finally, the data that could be included in the present study were not homogeneously available across all latitudes and longitudes, which may have biased our analyses concerning spatial variability. Future analyses filling such gaps may thus reveal different patterns of geographic variation, which could perhaps be related to warming patterns at different spatial scales.

In conclusion, we have shown a strong speciesspecific component to the response to climate change, especially for first arrival dates, suggesting that different populations of the same species respond consistently. This important conclusion represents the basis for comparative studies attempting to identify ecological or life-history attributes of species that are associated with a rapid response to climatic changes. Moreover, our results clearly indicate that the geographic setting, which ultimately determines the rate of change in climatic conditions, has to be taken into account when analysing phenological responses at wide geographical scales.

Acknowledgements. We thank the people who provided the unpublished sources of data included in this article, in particular, N. Jonzén, E. Knudsen, L. Sokolov, F. Spina, P. Suopajärvi and M. Zalakevicius. We are also indebted to T. Sparks for providing some of the time series from Great Britain, and to T. Ergon, A. Linden and N. Jonzén for thorough discussion and comments on statistical analyses. Finally, we thank C. Both and an anonymous referee for insightful comments on the manuscript.

\section{LITERATURE CITED}

Ahas R, Aasa A (2006) The effects of climate change on the phenology of selected Estonian plant, bird and fish populations. Int J Biometeorol 51:17-26

Ahola M, Laaksonen T, Sippola K, Eeva T, Rainio K, Lehikoinen E (2004) Variation in climate warming along the migration route uncouples arrival and breeding dates. Glob Change Biol 10:1610-1617

Barrett RT (2002) The phenology of spring bird migration to north Norway. Bird Study 49:270-277

Berthold P (1991) Patterns of avian migration in light of current global 'greenhouse' effects: a central European perspective. Acta Congr Int Ornithol 20:780-786

Berthold P, Helbig AJ, Mohr G, Querner U (1992) Rapid microevolution of migratory behavior in a wild bird species. Nature 360:668-670

Both C (2007) Comment on 'Rapid advance of spring arrival dates in long-distance migratory birds'. Science 315:598b

Both C, te Marvelde L (2007) Climate change and timing of avian breeding and migration throughout Europe. Clim Res 35:93-105

Both C, Artemyev AV, Blaauw B, Cowie RJ and others (2004) Large-scale geographical variation confirms that climate change causes birds to lay earlier. Proc R Soc Lond B Biol Sci 271:1657-1662

Both C, Bouwhuis S, Lessells CM, Visser ME (2006) Climate change and population declines in a long-distance migratory bird. Nature 441:81-83

Browne SJ, Aebischer NJ (2003) Temporal changes in the migration phenology of turtle doves Streptopelia turtur in Britain, based on sightings from coastal bird observatories. J Avian Biol 34:65-71

Coppack T, Both C (2002) Predicting life-cycle adaptation of migratory birds to global climate change. Ardea 90: 369-378

Cotton PA (2003) Avian migration phenology and global climate change. Proc Natl Acad Sci USA 100:12219-12222

Cramp S (1998) The complete birds of the western Palearctic on CD-ROM. Oxford University Press, Oxford

Crawley MJ (1993) GLIM for ecologists. Blackwell Science, Oxford

Dunn PO (2004) Breeding dates and reproductive performance. Adv Ecol Res 35:67-85 
Felsenstein J (1985) Phylogenies and the comparative method. Am Nat 125:1-15

Forchhammer MC, Post E, Stenseth NC (2002) North Atlantic Oscillation timing of long- and short-distance migration. J Anim Ecol 71:1002-1014

Gienapp P, Leimu R, Merilä J (2007) Responses to climate change in avian migration time-microevolution versus phenotypic plasticity. Clim Res 35:25-35

Gordo O (2007) Why are bird migration dates shifting? A review of weather and climate effects on avian migratory phenology. Clim Res 35:37-58

Gottlander K (1987) Variation in the song rate of the male pied flycatcher Ficedula hypoleuca: causes and consequences. Anim Behav 35:1037-1043

Harvey PH, Pagel MD (1991) The comparative method in evolutionary biology. Oxford University Press, Oxford

Hüppop O, Hüppop K (2003) North Atlantic Oscillation and timing of spring migration in birds. Proc R Soc Lond B Biol Sci 270:233-240

IPCC (Intergovernmental Panel on Climate Change) (2001) Climate change 2001: the scientific basis. Cambridge University Press, Cambridge

Jenni L, Kéry M (2003) Timing of autumn bird migration under climate change: advances in long-distance migrants, delays in short-distance migrants. Proc R Soc Lond B Biol Sci 270:1467-1471

Jonzén N, Lindén A, Ergon T, Knudsen E and others (2006) Rapid advance of spring arrival dates in long-distance migratory birds. Science 312:1959-1961

Jonzén N, Lindén A, Ergon T, Knudsen E and others (2007a) Response to comment on 'Rapid advance of spring arrival dates in long-distance migratory birds'. Science 315:598c

Jonzén N, Hedenström A, Lundberg P (2007b) Climate change and the optimal arrival of migratory birds. Proc R Soc Lond B Biol Sci 274:269-274

Klein Tank AMG, Wijngaard JB, Konnen GP, Bohm R and others (2002) Daily dataset of 20th-century surface air temperature and precipitation series for the European climate assessment. Int J Climatol 22:1441-1453

Knudsen E, Lindén A, Ergon T, Jonzén N and others (2007) Characterizing bird migration phenology using data from standardized monitoring at bird observatories. Clim Res 35:59-77

Kokko A (1999) Competition for early arrival in migratory birds. J Anim Ecol 68:940-950

Lehikoinen E, Gustafsson E, Aalto T, Alho P and others (2003) Varsinais-Suomen Linnut. Turun Lintutieteellinen Yhdistys r.y., Turku

Lehikoinen E, Sparks TH, Zalakevicius M (2004) Arrival and departure dates. Adv Ecol Res 35:1-31

Loxton RG, Sparks TH, Newnham JA (1998) Spring arrival dates of migrants in Sussex and Leicestershire (19661996). Sussex Bird Rep 50:182-196

Menzel A, Fabian P (1999) Growing season extended in Europe. Nature 397:659

Menzel A, Sparks TH, Estrella N, Koch E and others (2006) European phenological response to climate change matches the warming pattern. Glob Change Biol 12:1969-1976

Mitrus C, Sparks TH, Tryjanowski P (2005) First evidence of phenological change in a transcontinental migrant wintering in the Indian subcontinent: the red-breasted flycatcher Ficedula parva. Ornis Fenn 82:13-19

Moberg A, Jones PD, Lister D, Walther A and others (2006) Indices for daily temperature and precipitation extremes in Europe analyzed for the period 1901-2000. J Geophys Res 111:D22106

Møller AP (2004) Protandry, sexual selection and climate change. Glob Change Biol 10:2028-2035

Møller AP (2007) Tardy females, impatient males: protandry and divergent selection on arrival date in the two sexes of the barn swallow. Behav Ecol Sociobiol 61:1311-1319

Møller AP, Birkhead TR (1994) The evolution of plumage brightness in birds is related to extra-pair paternity. Evolution 48:1089-1100

Møller AP, Merilä J (2004) Analysis and interpretation of long-term studies investigating responses to climate change. Adv Ecol Res 35:110-130

Møller AP, de Lope F, Saino N (2004) Parasitism, immunity and arrival date in a migratory bird. Ecology 85:206-219

Nussey DH, Postma E, Gienapp P, Visser ME (2005) Selection on heritable phenotypic plasticity in a wild bird population. Science 310:304-306

Parmesan C, Yohe G (2003) A globally coherent fingerprint of climate change impacts across natural systems. Nature 421:37-42

Peintinger M, Schuster S (2005) Veränderungen der Erstankünfte bei häufigen Zugvogelarten in Südwestdeutschland. Vogelwarte 43:161-169

Pigliucci M (2005) Evolution of phenotypic plasticity: Where are we going now? Trends Ecol Evol 20:481-486

Pulido F (2007) Phenotypic changes in spring arrival: evolution, phenotypic plasticity, effects of weather and condition. Clim Res 35:5-23

Rainio K, Laaksonen T, Ahola M, Vähätalo AV, Lehikoinen E (2006) Climatic responses in spring migration of boreal and arctic birds in relation to wintering area and taxonomy. J Avian Biol 37:507-515

Rainio K, Tøttrup AP, Lehikoinen E, Coppack T (2007) Effects of climate change on the degree of protandry in migratory songbirds. Clim Res 35:107-114

Rauhala P (1994) Kemin-Tornion seudun linnusto 2. Raahen Kirjatyö Oy, Kemi

Root TL, Price JT, Hall KR, Schneider SH, Rosenzweig C, Pounds JA (2003) Fingerprints of global warming on wild animals and plants. Nature 421:57-60

Rubolini D, Ambrosini R, Caffi M, Brichetti P, Armiraglio S, Saino N (2007) Long-term trends in first arrival and first egg laying dates of some migrant and resident bird species in northern Italy. Int J Biometeorol 51:553-563

Saino N, Ambrosini R (2007) Climatic connectivity between Africa and Europe may serve as a basis for phenotypic adjustment of migration schedules of trans-Saharan migratory birds. Glob Change Biol (in press), doi: 10.1111/ j.1365-2486.2007.01488.x

Saino N, Rubolini D, Jonzén N, Ergon T, Montemaggiori A, Stenseth NC, Spina F (2007) Temperature and rainfall anomalies in Africa predict timing of spring migration in trans-Saharan migratory birds. Clim Res 35:123-134

Schwartz MD, Ahas R, Aasa A (2006) Onset of spring starting earlier across the Northern Hemisphere. Glob Change Biol 12:343-351

Sibley CG, Ahlquist JE (1990) Phylogeny and classification of birds: a study in molecular evolution. Yale University Press, New Haven, CT

Sokolov LV, Markovets MY, Shapoval AP, Morozov YG (1998) Long-term trends in the timing of spring migration of passerines on the Courish Spit of the Baltic Sea. Avian Ecol Behav 1:1-21

Sparks TH, Mason CF (2001) Dates of arrivals and departures of spring migrants taken from Essex Bird Reports 1950-1998. Essex Bird Rep 1999:154-164

Sparks TH, Roberts DR, Crick HQP (2001) What is the value of first arrival dates of spring migrants in phenology? Avian Ecol Behav 7:75-85 
Sparks TH, Bairlein F, Bojarinova JG, Hüppop H and others (2005) Examining the total arrival distribution of migratory birds. Glob Change Biol 11:22-30

Spottiswoode CN, Tøttrup AP, Coppack T (2006) Sexual selection predicts advancement of avian spring migration in response to climate change. Proc R Soc Lond B Biol Sci 273:3023-3029

Stervander M, Lindstrom A, Jonzén N, Andersson A (2005) Timing of spring migration in birds: long-term trends, North Atlantic Oscillation and the significance of different migration routes. J Avian Biol 36:210-221

Stöckli R, Vidale PL (2004) European plant phenology and climate as seen in a 20-year AVHRR land-surface parameter dataset. Int J Remote Sens 25:3303-3330

Tøttrup AP, Thorup K, Rahbek C (2006) Patterns of change in timing of spring migration in North European songbird

Submitted: February 20, 2007; Accepted: October 30, 2007 populations. J Avian Biol 37:84-92

Tryjanowski P, Kuzniak S, Sparks TH (2002) Earlier arrival of some farmland migrants in western Poland. Ibis 144:62-68

Vähätalo AV, Rainio K, Lehikoinen A, Lehikoinen E (2004) Spring arrival of birds depends on the North Atlantic Oscillation. J Avian Biol 35:210-216

Walther GR, Post E, Convey P, Menzel A and others (2002) Ecological responses to recent climate change. Nature 416:389-395

Zalakevicius M, Zalakeviciute R (2001) Global climate change impact on birds: a review of research in Lithuania. Folia Zool (Brno) 50:1-17

Zalakevicius M, Bartkeviciene G, Raudonikis L, Janulaitis J (2006) Spring arrival response to climate change in birds: a case study from eastern Europe. J Ornithol 147 : $326-343$

Proofs received from author(s): December 14, 2007 